\title{
Inhibition of the $\alpha$-Ketoglutarate Dehydrogenase Complex from Bakers' Yeast by Acetaldehyde and Glyoxylate
}

\author{
By Takashi Hirabayashi* and Tokuya Harada \\ The Institute of Scientific and Industrial Research, \\ Osaka University, Suita, Osaka \\ Received January 14, 1972
}

A condensation reaction between $\alpha$-ketoglutarate and acetaldehyde to form 5-hydroxy4-ketohexanoic acid was originally detected in studies on alcohol metabolism in vitro in systems from mammals ${ }^{13}$ and yeast. ${ }^{2,31}$ This reaction is analogous to the formation of acetoin from pyruvate plus acetaldehyde, or to the formations of other acyloins from $\alpha$-keto acids plus aldehydes.
$\alpha$-Ketoglutarate also reacts with glyoxylate A synergistic decarboxylation of $\alpha$-ketoglu tarate and glyoxylate catalyzed by enzyme from bacteria or mammalian tissues has beer reported by many workers. ${ }^{4-121}$ This reactior was first demonstrated by Crawhall and Watts ${ }^{5}$ and the enzyme which catalyzes it was puri fied about 100-fold by Koch and Stokstad ${ }^{8}$ and by Stewart and Quayle ${ }^{11}$ from rat anc

Table I. Carboligase Activity of the $\alpha$-Kietoglutarate Dehydrogenase Complex

\begin{tabular}{l} 
Substrate \\
\cline { 2 - 2 } \\
Glyoxylate-U-14C \\
Glyoxylate-U-14C plus $\alpha$-ketoglutarate \\
Acetaldehyde \\
Acetaldehyde plus $\alpha$-ketoglutarate
\end{tabular}

* Present address: The Central Research Institute, Suntory Ltd., 2-Chome 43, Dojimanaka, Kitaku, Osaka. 
pig liver mitochondria, respectively.

Recently, Schlossberg et al. ${ }^{13)}$ and Saito et al. ${ }^{14}$ reported that $\alpha$-ketoglutarate dehydrogenase complexes prepared from beef heart and pig heart, respectively, also catalyzed the carboligase reaction between $\alpha$-ketoglutarate and glyoxylate or acetaldehyde. The present paper reports that an $\alpha$-ketoglutarate dehydrogenase complex from bakers' yeast catalyzes the carboligase reaction between $\alpha$-ketoglutarate and glyoxylate or acetaldehyde and is inhibited by acetaldehyde or glyoxylate.

The $\alpha$-ketoglutarate dehydrogenase complex was prepared from bakers' yeast (Oriental Yeast Co., Ltd.) by the method of Hirabayashi et al. ${ }^{15 ;}$ It was essentially homogenous



FIG. 1. Effects of Glyoxylate and Acetaldehyde on the $\alpha$-Ketoglutarate Dehydrogenase Complex from Bakers' Yeast.

Additions: $A$, none; $B, 2.5 \mathrm{~mm}$ glyoxylate; C, $5.0 \mathrm{~mm}$ acetaldehyde.

The reaction mixture contained 150 pmoles of potassium phosphate buffer ( $\mathrm{pH} \mathrm{7.2)} 0.5 \mu$ mole of $\mathrm{MgCl}_{2}, 0.08 \mu$ mole of CoA, $5 \mu$ moles of L-cysteine, $0.3 \mu$ mole of NAD, $0.5 \mu$ mole of TPP, sodium $\alpha$ ketoglutarate and glyoxylate or acetaldehyde in a final volume of $2.0 \mathrm{ml}$. The reaction was initiated at $25^{\circ} \mathrm{C}$ by the addition of enzyme and the rate of formation of $\mathrm{NADH}$ was followed at $340 \mathrm{~m} \mu$ using a Hitachi, model 124, spectrophotometer in conjunction with i Hitachi, model QPD 34, recorder. One unit of $\alpha$-ketoglutarate dehydrogenase complex is defined as the amount catalyzing the oxidation of one $\mu$ mole of $\alpha$-ketoglutarate per min. upon ultracentrifugation and had a sedimentation coefficient $\left(s_{20, w}\right)$ of $20.9 \mathrm{~S}$.

As shown in Table $\mathrm{I},{ }^{14} \mathrm{CO}_{2}$ formation from glyoxylate- $\mathrm{U}-{ }^{14} \mathrm{C}$ was strongly enhanced by addition of $\alpha$-ketoglutarate. Furthermore, the formation of 5-hydroxy-4-ketohexanoic acid from acetaldehyde and $\alpha$-ketoglutarate was catalyzed by the $\alpha$-ketoglutarate dehydrogenase complex. The mechanism of the synergistic decarboxylation of $\alpha$-ketoglutarate and glyoxylate or acetaldehyde seemed to be very similar to that resulting in acetoin formation from pyruvate and acetaldehyde catalyzed by the pyruvate dehydrogenase complex. ${ }^{16}$

Glyoxylate and acetaldehyde markedly inhibited the reduction of $\mathrm{NAD}^{+}$catalyzed by the $\alpha$-ketoglutarate dehydrogenase complex. Glyoxylate and acetaldehyde caused mixed type inhibition of the overall oxidation activity of the $\alpha$-ketoglutarate dehydrogenase complex with $\alpha$-ketoglutarate (Fig. 1). The Ki value of glyoxylate was $3.3 \mathrm{mM}$ and that of acetaldehyde was $7.2 \mathrm{~mm}$. The present results on the inhibition of the $\alpha$-ketoglutarate dehydrogenase complex indicate that the functions of this complex in yeast may be regulated by the metabolism of ethanol through the influence of the latter on the level of acetaldehyde.

\section{REFERENCES}

1) R. J. Bloom, P. G. Guller, J. G. Westerfeld and W. W. Westerfeld, Biochemistry, 5, 3211 (1966).

2) T. Hirabayashi and T. Harada, Agr. Biol. Chem., 33, 276 (1969).

3) T. Hirabayashi and T. Harada, ibid., 34, 257 (1970).

4) W. Franke and G. Jilge, Arch. Mikrobiol., 39, 88 (1961).

5) J. C. Crawhall and R. W. E. Watts, Biochem. J., 85, 163 (1962).

6) M. Okuyama, S. Tsuiki and G. Kikuchi, Biochim. Biophys. Acta, 110, 66 (1965).

7) H. Kawasaki, M. Okuyama and G. Kikuchi, J. Biochem., 59, 419 (1966).

8) J. Koch and E. L R. Stokstad, Biochem. Biophys. 
Res. Commun., 23585 (1966).

9) T. Moriyama and G. Yui, Biken J., 9, 263 (1966).

10) J. Koch, E. L. R. Stokstad, H. E. Williams and L. H. Smith, Jr., Proc. Natl. Acad. Sci. U.S., 57, 1123 (1967).

11) P. R. Stewart and J. R. Quayle, Biochem. J., 102, 885 (1967).

12) M. A. Schlossberg, D. A. Richert, R. J. Bloom and W. W. Westerfeld, Biochemistry, 7, 333 (1968).

13) M. A. Schlossberg, R. J. Bloom, D. A. Richert and W.W. Westerfeld, Biochemistry, 9, 1148 (1970).

14) T. Saito, S. Tuboi, Y. Nishimura and G. Kikuchi, J. Biochem., 69, 265 (1971).

15) T. Hirabayashi and T. Harada, Biochem. Biophys. Res. Commun, 45, 1369 (1971).

16) M. C. Karunairatman, J. Spizizen and H. Gest, Biochim. Biophys. Acta, 29, 649 (1958).

17) O. H. Lowry, N.J. Rosebrough, A. L. Farr and R. J. Randall, J. Biol. Chem., 193, 265 (1951). 